\title{
A New Approach to Measuring the Correlation of Organizational Alignment and Performance
}

DOI: 10.7595/management.fon.2017.0029

\begin{abstract}
Research Questions: This paper focuses on measuring the alignment of organizational elements. Motivation: Although several authors have analyzed this topic, there are few papers in which a concept for measuring the alignment of key elements of the organization is proposed (Simons, 2005; Sadeghi, 2011; Trevor \& Varcoe, 2017). In previous research, the concept of alignment is usually defined through categorical variables and different organizational configurations are suggested (Mintzberg, 1980). Thus, this paper aims to propose a new approach to measuring organizational elements and their alignment. Idea: Based on the literature review we determined the organizational model for conducting the research in companies listed on the top 300 companies in Serbia. Data: On the sample of 57 respondents the results confirmed the defined hypothesis by which the alignment of the organizational elements has a positive correlation with the organizational performance. Tools: In order to measure the organizational elements we defined the 7-level scale which enables measuring the alignment of organizational elements. Findings: The research results confirm that it is necessary to look at the solutions based on some organizational elements simultaneously. However, in order to confirm the validity and reliability of the results, it is necessary to conduct a research on a larger sampling frame, since the sample from this research is relatively small in comparison to the total population. Contribution: The defined scale can be used as a control tool for checking the proposed organizational design solutions in practice. Also, the rules of alignment of organizational elements can be applied at different hierarchical levels in the organization, which will be the subject of future research of the authors.
\end{abstract}

Keywords: organizational elements measuring, organizational alignment, organizational structure, measuring performance system, behaviour formalization.

JEL Classification: D02, L25, L22.

\section{Introduction}

During the last three decades, the management of organizational systems has increasingly been based on quantitative methods, which gives objectivity to the process of management and proposed solutions. Another area of management in which measurement methods are increasingly being used is the area of designing the organization.

In previous years, the requested organizational design solutions were within defined organization configurations, which included predefined values of different elements of the organization (Woodward, 1958; Khandwalla, 1973; Mintzberg, 1979). Even then, the concept of fit or alignment of organizational elements is introduced as an important concept in research (Miller, 1992; Siggelkow, 2001; Kathuria, Joshi \& Porth, 2007; Aleksic \& Rasic Jelavic, 2017). The alignment of organizational elements implies internal alignment of elements and compliance of organizational solutions with external factors in the environment (Lawrence \& Lorsch, 1967; Mintzberg, 1979; Siggelkow, 2001; Sadeghi, 2011). Khandawalla's research related to this topic showed that even if there is no single organizational variable or the state of some organizational ele- 
ment that is significantly related to the results of an organization, there are certain modalities of organizational elements intercorrelation which appear only in successful organizations (Khandwalla,1973).

In this study, we aimed to explore the correlation between alignment of organizational elements and the effectiveness of an organization. The variables values of the organizational elements are not defined by categorical measurement scales (i.e., centralized or decentralized structure), but by the ordinal scales and values. For this purpose, a survey was conducted. We collected the data on of the organizational elements and the performances that organizations achieved in the observed period.

\section{Literature Review}

One of the main topics related to the strategy implementation and organizational design is the internal or horizontal alignment of elements of an organization (Miller, 1992; Siggelkow, 2001; Kathuria, Joshi, \& Porth, 2007). Without fit or alignment of organizational elements, you cannot fully expect the realization of defined strategic objectives (Sender, 1997; Kaplan \& Norton, 2006). There are different research papers which also imply the significance of this topic (Trevor \&Varcoe, 2017;Walter, Kellermanns, Floyd, Veiga\&Matherne 2013). Kaplan and Norton (2008) find that 60 to $80 \%$ of companies fail in achieving the objectives set in their strategic plans.

In addition to the contingency approach and theories that deal with the alignment of organizational elements with the environment and strategy (Woodward, 1958; Lawrence \& Lorsch, 1967; Thompson, 1967; Mintzberg, 1979; Sadeghi, 2011), some authors pointed out the importance of internal organizational elements alignment (Khandwalla, 1973; Mintzberg, 1979; Galbraith, Downey, \& Kates, 2002; Daft, 2003; Simons, 2005). Similarly, Siggelkow (2001) highlights the differences between the internal alignment of activities (whether there is a coherent activity configuration) and external alignment with the environment (whether there is an alignment with environmental conditions). Usually, organizations are observed as systems composed of mutually dependent and supportive elements (Miller \& Friesen, 1984), and as highly integrated systems whose performance is determined by the level of alignment of the main elements (Nadler, Tushman \& Nadler, 1997).

One of the most recognizable research works related to this topic is Mintzberg's hypothesis by which the effectiveness of an organization is influenced by the internal consistency between the elements of an organization (Mintzberg, 1980). His configuration hypothesis speaks of the necessity for coherence between elements of organization or "design parameters". Mintzberg assumes that there are "natural clusters" design parameters configuration and contingency factors. According to Mintzberg (1980), there is no infinite set of permutations and combinations of elements of the organization. There are subgroups of elements" properties within which the elements are complementary, that is, aligned.

McKinsey's consultants formulated a new framework for a different perspective (Waterman, Peters \& Phillips, 1980). A model that should provide a better understanding of organization included 7 elements (7S): strategy, structure, system, shared values, style, staff and skills. The scheme of the model shows the importance of interconnection of the elements. The central premise is that it is difficult, or even impossible to make significant progress in one area without simultaneous changes in other areas. They conclude that the organizational changes that ignore all aspects of an organization and their connection have little chance to succeed.

In addition to the importance of aligning the elements of an organization, Richard Daft provides some indicators for measuring the characteristics and quantification of elements (Daft, 2003). He measures the level of formalization by the number of employees which are suitable for a particular position. The span of control can be quantified by a number of employees suitable for a particular position. Employee qualification is shown as the average number of years of staff education; the number of employees measures the size of the organization, etc.

According to Simons (2005), the alignment of the organizational elements plays a crucial role in a successful strategy implementation. He defined the alignment of the elements through four spans: the span of control, the span of accountability, the span of influence, and the span of support. The four spans are defined by the design of these four organizational elements (respectively): unit structure, diagnostic control systems, interactive networks and shared responsibilities. According to Simons, in order to have a successful strategy implementation it is essential to have defined spans for each position and organizational unit. Alignment means that the sum of the control span and the span of support is equal to the sum of the accountability span and the range of influence. 
The following table is the summary of the listed research related to the internal alignment of organizational elements.

Table 1: Basic organizational concepts related to internal alignment

\begin{tabular}{|c|c|c|c|}
\hline Author(s) & Organizational elements & Designing principles & Alignment of elements \\
\hline Mintzberg(1980) & $\begin{array}{l}\text { Basic elements of an organization } \\
\text { Basic mechanisms of coordination } \\
\text { Systems of planning and control }\end{array}$ & $\begin{array}{l}\text { Congruence hypothesis, } \\
\text { configuration hypothesis, and } \\
\text { extended configuration } \\
\text { hypothesis }\end{array}$ & $\begin{array}{l}\text { Configuration hypothesis; } \\
\text { Structural configurations }\end{array}$ \\
\hline Waterman et al. (1980) & $\begin{array}{l}\text { Structure, Strategy, System, Skills, } \\
\text { Style, Staff, Shared Values }\end{array}$ & $\begin{array}{l}\text { Aligning organizational element } \\
\text { with situational factors }\end{array}$ & $\begin{array}{l}\text { The change of one element } \\
\text { implies the change in other } \\
\text { elements }\end{array}$ \\
\hline Richard Daft (2003) & Organizational structure & $\begin{array}{l}\text { Design based on principles of } \\
\text { contiguous approach }\end{array}$ & $\begin{array}{l}\text { There is a dependence } \\
\text { between elements; } \\
\text { A proposal for the } \\
\text { quantification of elements }\end{array}$ \\
\hline Robert Simons (2005) & $\begin{array}{l}\text { Four levers of organizational } \\
\text { design }\end{array}$ & $\begin{array}{l}\text { To align organizational } \\
\text { elements with the four } \\
\text { determinants of success }\end{array}$ & $\begin{array}{l}\text { Span of control + Span of } \\
\text { support = Span of } \\
\text { accountability. + Span of } \\
\text { influence }\end{array}$ \\
\hline
\end{tabular}

Based on the previous literature review, we defined a model of three elements: organizational structure, performance measurement system and behaviour formalization. Organizational structure is traditionally considered as a core element in an organization. The importance of this element stems from the influence that it has on the resource allocation and organizational activities, as well as in defining the positions of power and authority (Král \& Králová, 2016; Csaszar, 2012). The second component of the organization is the performance measurement system, which is a complement to the span of accountability created by defining the organizational structure. Performance measurement as an element of the organization can be found in the models of several authors, but different terms are used: the award system (Galbraith, Downey, \& Kates, 2002), the diagnostic control system (Simons, 2005), performance and rewards (Kaufman, 1988; Galbraith, Downey, \& Kates, 2002). The last element in the organization's model is behavior formalization, that is, the extent to which employee behaviour is guided and limited by rules and procedures (Mintzberg, 1979; ClaverCortés, Molina-Azorín, \& Pertusa-Ortega, 2012). This element is connected with the organizational culture, because, like culture, behaviour formalization through the definition of desirable actions has an impact on employees' control, their decisions and activities (O'Reilly, 1989).

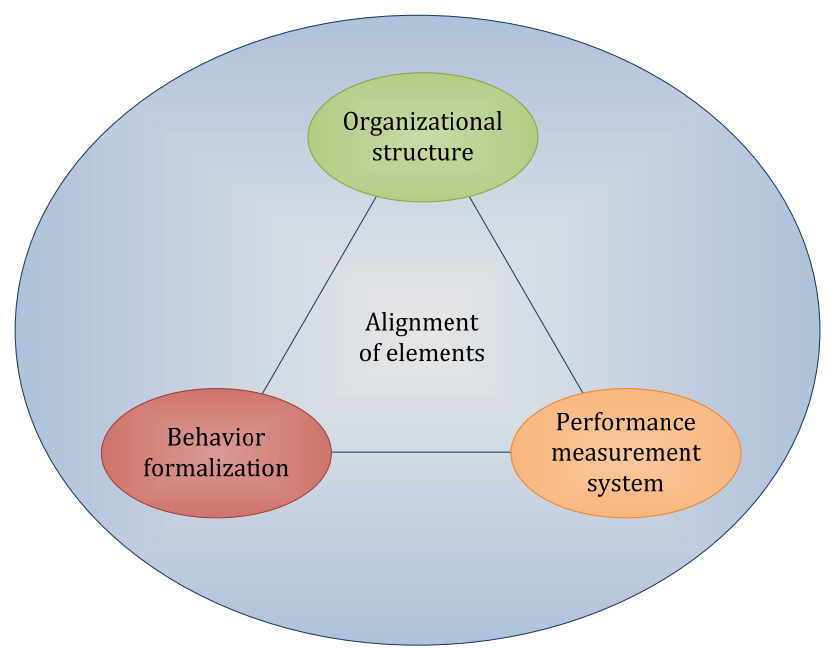

Figure 1: Model of organization (Source: Authors)

All of the above mentioned authors used some of the criteria of effectiveness in their research in order to confirm the assumptions about organizational solutions. There are also many other authors who have analyzed organizational design solutions and organizational performance (Rivkin \& Siggelkow, 2003; Yoo, Boland Jr. \& Lyytinen, 2006; Kohlbacher \& Reijers, 2013; Liozu, Hinterhuber\& Somers, 2014). Similarly, it is assumed in this article that the organizational effects are related to the internal consistency of the mentioned organizations elements, and that the greater alignment of the elements is related to the better organizational performance. Thus, we set the following hypothesis: 
Hypothesis: The alignment of an organization's elements has a positive correlation with the organizational performance.

In order to demonstrate the impact the alignment of elements has on the organizational efficiency, we conducted a research to collect data on the current state of the elements, as well as the results by the defined efficiency criteria that organizations have achieved.

\section{Methodology}

In order to achieve a higher level of reliability, before the research we conducted the training of the interviewers who were to do the examinations. The training was necessary due to the specificity of interpretation of the questions in the questionnaire and reducing the misunderstanding by the respondents. The technique used in the research was questionnaire with closed and open-ended questions, which were developed for of this research.

\subsection{Sample explanation}

The survey was conducted in the sampling frame of the first 300 companies in Serbia ranked according to the level of their business income (annual list "TOP 300" companies in Serbia published by the "Ekonomist" magazine). The data are annually published in a special edition of the "Ekonomist" magazine and represent the official data given to the Agency for Business Register at the end of each year. In the sampling frame there are firms from 22 different sectors, whose business income is more than 20 million euro and where $95 \%$ of the firms come from the group of medium-sized and large enterprises.

The research was possible in those companies which we had access to, so the sample was reduced to 63 companies. More than half of the total capital of all companies is concentrated in this group of companies $(53 \%)$, or almost half of the funds $(43.6 \%)$. By the level of operating revenues, the TOP 300 companies have achieved almost half of all companies' turnover (45.1\%), that is, more than a third of net profits (37.6\%), and net losses (34.6\%). These companies employ $25 \%$ of the total number of employees in all companies in the Republic of Serbia.

All questionnaires were distributed in person, by the trained interviewers. In total, 63 directors from the organizations filled in the questionnaires, 6 of which did not meet the criteria of the survey, so they were not taken into consideration for further analysis. A total of 57 questionnaires were analyzed. All the respondents were the representatives of top management that is, they were at the position of the first hierarchical level below CEO. Within the sampling frame, the sample is a nationally representative, randomly unstated sample. To increase the reliability of the collected data and avoid possible mistakes, double entry of data from the questionnaire was conducted. In the research we calculated the variance as measure of organizational alignment as well as the correlation coefficients between the examined variables. As a support we used the SPSS software.

\subsection{Measuring the variables of the organizations' elements}

The variable of the organizational structure which was measured was the span of control. Under the term "control" we assume the influence, permissions, and resources of the organization, assigned to a position for execution and disposal, in order to achieve the objectives for which a position is defined (Ouchi \& Dowling, 1974; Meier \& Bohte, 2000). The span refers to the width or the distance between the two extreme values. Thus, the span of control implies the size of the influence, permissions, and resources assigned to a particular position (Wong et al., 2015).

The variable span of control is operationalized with a seven-level scale which has been developed for this research. The scale has provided the tool for measuring the values of the element. The scale has 7 numerals (numbers in this case) and rules for assigning the proper number to each span of control variable. Assigning numerals to each object in the research has been conducted based on the filled questionnaires.

The assumed principle for determining the span of control for some position is that is the position has a span of control that depends on the resource allocation and responsibilities for that, as well as for all positions that are in the line chain directly or through other positions below the observed position. Thus, managerial po- 
sitions will have the span of control which is the sum of all positions below that certain position in the hierarchical chain, including the resources, influence, and authorization directly assigned to the position.

The respondents had the option to circle one or more activities in the questionnaire which, by the description, are suitable for their responsibilities in the organization. Activities in the questionnaire are categorized and described according to the Porter's value chain (Porter, 1980). Based on the circled activities and rules for assigning the numeral to a certain position, the span of control was determined for each respondent.

Based on the theory related to the performance measurement system, the variable measured for this organizational element is the span of accountability. The span of accountability is defined as the range of potential for achieving the effects of measurable variables assigned to a particular position (Simons, 2010; Christensen \& Lægreid, 2015). If the result of the organizational design was the allocation of responsibilities, the result of performance measurement system design is the allocation of responsibilities to organizational units (sectors, offices, departments, etc.), working groups, teams, all the way to the level of a particular position.

For measuring this variable, we also developed a 7-level scale, with the rules for assigning the numerals to the span of accountability variables for each organization. The scale was developed according to scales used by other researchers to measure the managerial responsibility (Ferris, Dulebohn, Frink, George-Falvy, Mitchell \& Matthews, 1997; Wood \& Winston, 2007). The allocation of the numerals to each object in the survey was done based on the filled questionnaires. For this variable there were 26 different statements related to the responsibilities of the respondents within the organization. All statements were divided into 4 groups: responsibility for efficiency and effectiveness of operations (6 statements), responsibility for financial results (6 statements), responsibility related to clients (7 statements), and responsibility related to learning and development of employees (7 statements).

In order to determine the internal consistency of the statements within the group, that is, measure the scale reliability, we used the alpha coefficient for the all items within 4 categories, respectively: $0.722,0.892,0.871$, and 0.834 . The result for the alpha coefficient suggests that the reliability of scale in the first group is acceptable $(>0.70)$, and in the remaining three groups is high (>0.80) (George \& Mallery, 2003). Based on the values by the groups, we assigned one numeral from the 7-level scale as the span of control value.

The defined variable for measuring behavior formalization was a span of limitation. We defined the span of limitation as a range of limitations in activities that are defined by procedures, rules, norms, and values shared by members of an organization or a part of an organization. Behaviour formalization defines limitations in business behavior or rules of conduct that are related to organizational units (sectors, offices, departments, etc.), working groups, teams all the way to the level of the positions of the employees (Walsh \& Dewar, 1987; Michaels, Cron, Dubinsky, \& Joachimsthaler, 1988).

For the span of limitations, we also defined a measuring method through an appropriate measuring scale. The scale was developed according to the surveys and questionnaires developed for measuring employees' behaviour in organizations (Berson, Oreg, \& Dvir, 2008). The scale also contains 7 numerals to be comparable to scales that measure the span of control and the span of accountability. Numeral assignment to each object in the survey was performed based on the defined rules for the scale and the questionnaire responses. For this variable, there were 8 statements related to procedures, rules, norms and values shared within an organization. The alpha coefficient for all items is 0.8337 which signifies that the reliability of scale is high (>0.8) (George \& Mallery, 2003).

The author who proposed the quantification of the alignment of organizational elements is Robert Simons (Simons, 2005). He defined the alignment by a mathematical formula as an equality between the sum of the values of the elements that represent the supply of resources, on the one hand, and the elements that represent the demand for resources, on the other.

$$
\begin{gathered}
\text { Span of Control }+ \text { Span of Support = Span of Accountability }+ \text { Span of Influence } \\
\text { Span of Resources }=\text { Demand for Resources }
\end{gathered}
$$

Although this approach is intuitively desirable, because it is based on the ability to compile and compare the elements of an organization, there are numerous methodological preconditions that should be fulfilled for the proposed variables to be compiled and compared (Hubbard, 2014). However, the proposed model is the closest solution to the problem of the quantification of the organizational elements and their alignment based on the measured values. 
To determine the alignment of the organizational elements in this paper, we explicitly defined the variable organizational elements alignment. Theoretical explanations of the organizational element variables were the basis for defining this variable (Prado Sousa \& do Prado Leite, 2014). Alignment of elements is defined so that the highest value is achieved when all of the observed elements have the same values $(3-3-3,5-5$ 5 , etc.), and that the mismatch represents any other combination when the elements do not have the same values. It can also be said that a smaller mismatch is a deviation of one element for one place (e.g., 3 - 3 4) than when they differ in two places (3 - 3 - 5).

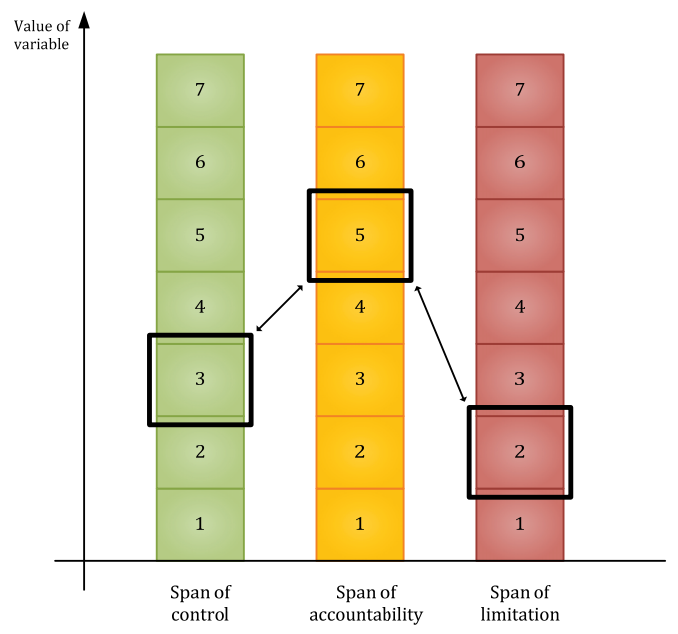

Figure 2: Measuring the alignment of the organizational elements (source: Authors)

Therefore, the compliance of all three elements is measured by the value of the standard deviation value, which is calculated according to the formula (Kovacic, 1994):

$$
\text { Alignment of organizational elements }=\sqrt{\frac{1}{n} \sum_{i=1}^{n}\left(x_{i}-\bar{x}\right)^{2}}
$$

where $n$ represents the number of organizational elements ( 3 in this case),

$\bar{x}(x-b a r)$ - arithmetic mean of organizational elements values,

$x_{i}-i$-th organizational element $(i=1,2,3)$.

Also, the same results (the correlation coefficients) are obtained if the variance of the organizational elements is selected for the independent variable.

The alignment of organizational elements will have a lower value when the elements are more aligned, and vice versa, a lower alignment will cause higher values of standard deviation, that is, the variable.

\subsection{Measuring the organizational performance}

For companies from the sampling frame, the annual reports were publicly available, containing various important data such as business revenue, business revenue growth, number of employees, EBITDA, capital, as well as other data from the company profile-sector, type of organization, location, etc.

The criteria of organizational performance were focused on productivity indicators, since they are the most objective and most common efficiency criteria used in research (Carton, 2004). For productivity criteria we used:

- Business Revenue / Average number of employees. In business revenues, unlike total income, there are no data on financial revenues arising from the sale of shares, bonds, a sale of shares in other legal entities or by interest and dividends, as a result of long-term investment in financial assets (Biddle, 2012).

- Ratio EBITDA / Average number of employees. This ratio is the data that allow comparing the realized profit without the effects of fixed assets (excluding depreciation costs), taxes and sources of funds (not including interest costs) (Kale, Ryan Jr., \& Wang, 2016).

For these two criteria, we also calculated the appropriate percentile ranks within the sector for each organization. The percentile rank is defined as the percentage of subjects in the observed group that has the 
value of the observed variable at or below a certain value (Dixon \& Massey Frank, 1950). Percentiles are used in many studies as a dependent variable (Zakari \& Poku, 2013; Abramo \& D'Angelo, 2014). Percentile ranks are calculated based on the data for all 300 organizations from the sampling frame because data on organizational effects are taken from the public reports, and not from the filled questionnaires. By using the percentile ranks of raw scores, we bypassed the influence of sectoral affiliation of the organizations and other factors that affect the performance indicators.

\section{Results and Discussion}

The independent variable in the model is the alignment of organizational elements, while the dependent variables are the organizational performance variables (Figure 3 ).

In our model, lower values of variance signify higher organizational alignment. Thus, when the alignment of organization's elements has a positive correlation with the organizational performance (dependent variables), variance negatively correlates with the organizational performance.

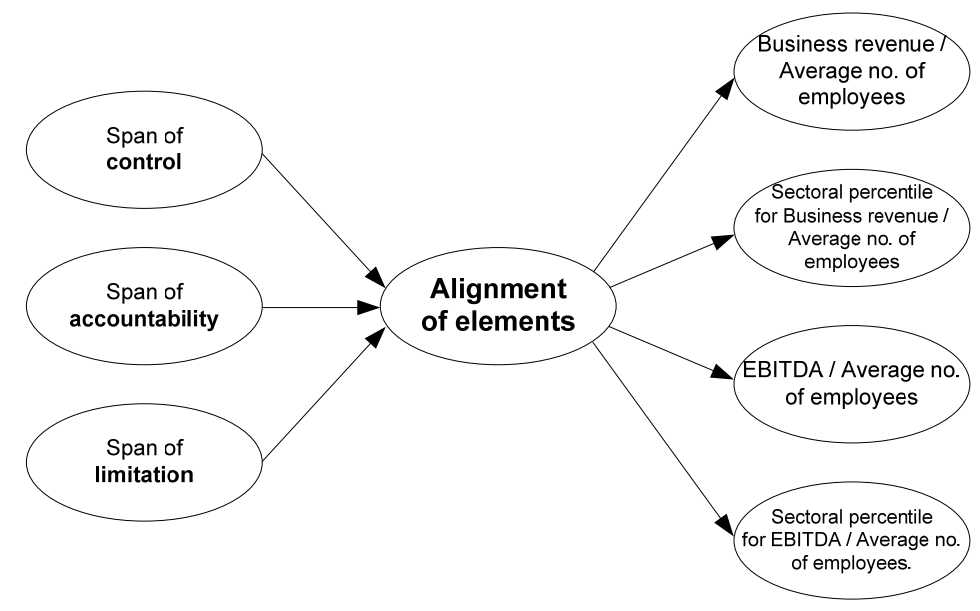

Figure 3: Research model

The correlation between the alignment of organizational elements and the efficiency criteria is expressed by the Spearman correlation coefficients. However, since the functional dependency between the tested variables does not have to be linear, and since the data are not normally distributed, in this study we used Spearman's correlation coefficient (Kovacic, 1994). The results of the dependency examination are shown in Table 2.

Table 2: Correlation between alignment of organizational elements and efficiency criteria

\begin{tabular}{|l|c|c|}
\hline \multicolumn{1}{|c|}{ Efficiency criterion } & Alignment of organizational elements \\
\hline Revenue/Average no. of employees & $r_{0}$ & Sig. \\
\hline Sectoral percentile Revenue/Avg no. of employees & $-.373^{\star *}$ & 0.004 \\
\hline EBITDA/ Average no. of employees & $-.430^{\star *}$ & 0.001 \\
\hline Sectoral percentile EBITDA/Avg no. of employees & $-.265^{\star}$ & 0.046 \\
\hline
\end{tabular}

**. Correlation is significant if the value of the test is lower than 0.01 (when a two-sided correlation test is conducted).

*. Correlation is significant if the value of the test is lower than 0.05 (when a two-sided correlation test is conducted).

The table shows the correlation coefficients and other data used to interpret the correlation between the organization's elements and the efficiency criteria. The following correlation coefficients were obtained for the most significant efficiency indicators:

- Business revenue/Average number of employees $\left(r_{0}=-0.373, p<0.01\right)$,

- Sectoral percentile for Business revenue/Average number of employees $\left(r_{0}=-0.430, p<0.01\right)$,

- EBITDA/Average number of employees $\left(r_{0}=-0.265, p<0.05\right)$

- Sectoral percentile for EBITDA/Average number of employees $\left(r_{0}=-0.283, p<0.05\right)$

The obtained correlation coefficients $\left(r_{0}\right)$ have a negative value, which means that there is an inversely proportional correlation between the values for the independent (compliance of the elements) and the de- 
pendent variables, signifying that greater alignment of the elements is in correlation with the better performance of the organization. For the first two dependent variables, the obtained correlation coefficients $\left(r_{0}\right.$ $\left.=-0.373, r_{0}=-0.430\right)$ indicate the medium strength of the correlation, while the other two variables $(r 0=-$ $0.265, \mathrm{r} 0=-0.283$ ) have weak correlations with the organizational alignment (Pallant, 2011). The calculated correlations are statistically significant for all variable values. A higher correlation between the variables in the model was determined when the percentile ranks of the sector of the economy were taken as efficiency criteria. Using percentile ranges reduces the differences between the different sectors of the economy of the observed organizations because the range of these values is between 0 and 100 .

The obtained determination coefficients explain how much the total variance of the dependent variable is assigned to the value of the variance of the independent variable (alignment of the elements). For example, alignment of elements helps to explain about $14 \%$ of the variance in Revenue/Average number of employees.

When interpreting the results of the performed analysis, we should take into consideration the fact that the sampling frame in the survey was the organizations that are on the list of the TOP 300 organizations in Serbia. The selection of the sampling frame has influenced the limitation of the value of the dependent variables (the efficiency indicators) (Trotter, 2012). Although among the TOP 300 organizations there are differences in terms of efficiency, it is possible that companies that are not on this list have a different distribution of dependent variable values. The problem of the range of values of variables occurs in situations where all objects are not taken into consideration, but only those whose variable values belong to some narrower range (Todorovic, 2008).

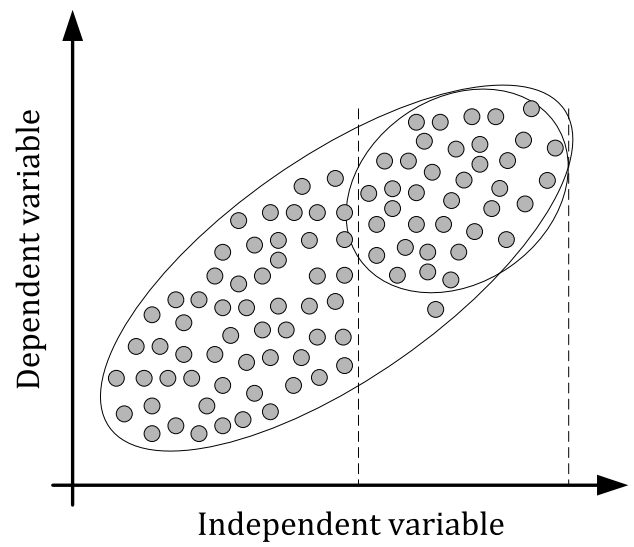

Figure 4: Correlation diagram for the selected sampling frame (Todorovic, 2008)

Figure 4 shows thea clear positive correlation between the independent and the dependent variable (elongated ellipse) when all cases are taken into account. However, limiting research to a narrower set of subjects (between two vertical lines) suggests a smaller correlation between the two variables.

Unlike previous research that used mostly categorical variables for the analysis of the organizational elements, in this paper we measured the values of the organizational elements by the mathematical calculation. For this research, we defined the measurement scales of organizational elements, according to which each element of the organization was assigned particular numerical values on a seven-level ordinal scale. The defined measurement scale represents a step forward in relation to the previous categorical measurements of the elements of the organization, which is one of the main contributions of this paper.

Also, the existing sample for which the survey was conducted represents a relatively small sample in comparison with the total population. Better conclusions could be drawn for the research conducted on a larger sample, including organizations with a lower business income.

One of the limitations of the research is measuring the variables of organizational elements, which has elements of subjectivity (Meier \& O'Toole Jr, 2013). Although precise descriptions of the characteristics of variables have been made, there is a certain degree of subjectivity in assessing the value of the elements on the scale from 1 to 7 . Further, in future research, other parameters of the elements included in the presented model and other organizational elements, should be included in the model. In addition to the organizational structure, performance measurement system, and behaviour formalization, the organization consists of other 
elements such as strategy, processes, reward system, organizational culture, human resources, etc. Also, the existing sample for which the survey was conducted represents a relatively small sample in relation to the total population. Better conclusions could be drawn if the research was repeated on a larger sample, including organizations with a lower business income.

\section{Conslusion}

There are multiple practical implications of the results of the research. First, the alignment of the elements is defined which can be used in the process of organizational design for both macro-organizational structure and individual parts of the organization at lower levels. The suggestions of organizational solutions can be tested using the model suggested in this paper to check if there are greater deviations in organizational elements' variables. Second, the proposed model can be used in the existing organizations as a practical tool to check the alignment of organizational elements and define the appropriate programmes of change.

This paper aimed to give a theoretical overview of the alignment of organizational elements and their connection with organizational effects. By defining the method of measuring the elements of the organization, we tried to contribute to solving the critical issue of organizational element alignment. The obtained results are in favour of the defined hypothesis according to which the compliance of organizational elements has a positive correlation with the organizational performance. Accordingly, when designing an organization or its parts, the designed solutions should be defined in such way to have values on the scale as close as possible, that is, there should be a greater alignment of the elements. The scale defined in this paper for measuring the elements' alignment can be used as a control tool for checking the proposed solutions in the process of organizational design.

Further, the research supports the postulate that it is necessary to simultaneously look at solutions by several elements of the organization, which is also the conclusion of other authors (Khandwalla, 1973;Mintzberg, 1980;Galbraith, Downey, \& Kates, 2002; Simons, 2005).

The paper gives a theoretical and empirical review of the alignment of organizational elements, and opens new issues that should be explored in future research. The future research directions should be oriented towards repetition of the research on a wider sampling frame to include the small and medium-sized organizations that are not included in the TOP 300 by the annual turnover. Secondly, the research should be conducted for more positions within the same organization. In this way, it would be possible to determine the values of the observed variables for multiple positions in the structure and to examine if the alignment between the variables is consistent within the organization. This would give the additional value to the research presented in this paper and provide even more important practical implications in the field of organizational design.

\section{REFERENCES}

[1] Abramo, G., \& D'Angelo, C. A. (2014). How do you define and measure research productivity? Scientometrics , 101 (2), 1129-1144. DOI:

[2] Aleksic, A., \&RasicJelavic, S. (2017). Testing for strategy-structure fit and its importance for performance. Management: journal of contemporary management issues, 22(1), 85-102.

[3] Berson, Y., Oreg, S., \& Dvir, T. (2008). CEO values, organizational culture and firm outcomes. Journa of Organizational Behavior , 29 (5), 615-633. DOI: 10.1002/job.499

[4] Biddle, J. (2012). The Introduction of the Cobb-Douglas Regression. The Journal of Economic Perspectives , 26 (2), 223-236.DOI: 10.1257/jep.26.2.223

[5] Carton, R. (2004). Measuring Organizational Performance: An Exploratory Study. University of Georgia.

[6] Csaszar, F. A. (2012). Organizational structure as a determinant of performance: Evidence from mutual funds. Strategic Management Journal, 33(6), 611-632. DOI: 10.1002/smj.1969

[7] Christensen, T., \& Lægreid, P. (2015). Performance and accountability-A theoretical discussion and an empirical assessment. Public Organization Review, 15 (2), 207-225.

[8] Claver-Cortés, E., F. Molina-Azorín, J., \& M. Pertusa-Ortega, E. (2012). Characteristics of organizational structure relating to hybrid competitive strategy:. Journal of Business Research , 65 (7), 993-1002. DOI: 10.1016/j.jbusres.2011.04.012

[9] Daft, R. L. (2003). Organization Theory and Design (8th ed.). Mason, Ohio: South-Western College Pub.

[10] Dixon, W. J., \& Massey Frank, J. (1950). Introduction To Statistical Analsis. New York: McGraw-Hill Book Company, Inc. 
[11] Ferris, G. R., Dulebohn, J. H., Frink, D. D., George-Falvy, J., Mitchell, T. R., \& Matthews, L. M. (1997). Job And Organizational Characteristics, Accountability, And Employee Influence. Journal of Managerial Issues , 9 (2), 162-175.

[12] Galbraith, J., Downey, D., \& Kates, A. (2002). Designing Dynamic Organizations: A Hands-on Guide for Leaders at All Levels. New York: Amacom.

[13] George, D., \& Mallery, P. (2003). Reliability analysis. SPSS for Windows, step by step: a simple guide and reference. Boston: Allyn \& Bacon.

[14] Hubbard, D. W. (2014). How to measure anything : finding the value of intangibles in business. Hoboken, New Jersey: John Wiley \& Sons, Inc.

[15] Kale, J. R., Ryan Jr., H. E., \& Wang, L. (2016). Outside employment opportunities, employee productivity, and debt discipline. Journal of Corporate Finance. In press. DOI: 10.1016/j.jcorpfin.2016.08.005

[16] Kaplan, R. S., \& Norton, D. P. (2006). Alignment: Using the Balanced Scorecard to Create Corporate Synergies. Harvard Business Press.

[17] Kaplan, R. S., \& Norton, D. P. (2008). The execution premium: Linking strategy to operations for competitive advantage.

[18] Kathuria, R., Joshi, P. M., \& Porth, S. J. (2007). Organizational alignment and performance: past, present and future. Management Decision , 45 (3), 503-517. DOI: 10.1108/00251740710745106

[19] Kaufman, R. (1988). Preparing useful performance indicators. Training \& Development Journal , 42 (9), 80-84.

[20] Khandwalla, P. N. (1973). Viable and Effective Organizational Designs of Firms. Academy of Management Journal, 16 (3), 481-495.

[21] Kovacic, Z. J. (1994). Multivarijaciona analiza. Beograd: Univerzitet u Beogradu, Ekonomski fakultet.

[22] Kohlbacher, M., \& Reijers, H. A. (2013). The effects of process-oriented organizational design on firm performance. Business Process Management Journal, 19(2), 245-262.

DOI: $10.1108 / 14637151311308303$

[23] Král, P., \&Králová, V. (2016). Approaches to changing organizational structure: The effect of drivers and communication. Journal of Business Research, 69(11), 5169-5174. DOI: 10.1016/j.jbusres.2016.04.099

[24] Lawrence, P. R., \& Lorsch, J. W. (1967). Organization and Environment: Managing Integration and Differentiation. Boston: Harvard University.

[25] Liozu, S., Hinterhuber, A., \& Somers, T. (2014). Organizational design and pricing capabilities for superior firm performance. Management Decision, 52(1), 54-78. DOI: 10.1108/MD-05-2013-0279

[26] Meier, K. J., \& Bohte, J. (2000). Ode to Luther Gulick: Span of Control and Organizational Performance. Administration \& Society, 32 (2), 115-137. DOI: 10.1177/00953990022019371

[27] Meier, K. J., \& O'Toole Jr, L. J. (2013). Subjective Organizational Performance and Measurement Error: Common Source Bias and Spurious Relationships. Journal of Public Administration Research \& Theory , 23, 429-456.

[28] Michaels, R. E., Cron, W. L., Dubinsky, A. J., \& Joachimsthaler, E. A. (1988). Influence of formalization on the organizational commitment and work alienation of salespeople and industrial buyers. Journal of Marketing Research, 376-383.

[29] Miller, D. (1992). Environmental Fit versus Internal Fit. Organization Science, 3 (2), 159-178. DOI: 10.1287/orsc.3.2.159

[30] Miller, D., \& Friesen, P. H. (1984). Organizations: A Quantum View. Prentice Hall.

[31] Mintzberg, H. (1980). Structure in 5's: A Synthesis of the Research on Organization Design. Management Science, 26 (3), 322-341.

[32] Mintzberg, H. (1979). The Structuring of Organization. New Jersey: Prentice-Hall.

[33] Nadler, D., Tushman, M., \& Nadler, M. B. (1997). Competing by Design: The Power of Organizational Architecture. Oxford: Oxford University Press.

[34] O'Reilly, C. (1989). Corporations, culture, and commitment: Motivation and social control in organizations. California Management Review, 31 (4), 9-25.

[35] Ouchi, W. G., \& Dowling, J. B. (1974). Defining the Span of Control. Administrative Science Quarterly , 357-365.

[36] Pallant, J. (2011). SPSS Survival Manual - A step by step guide to data analysis using SPSS. Allen \& Unwin.

[37] Prado Sousa, H., \& do Prado Leite, J. C. (2014). Modeling Organizational Alignment. International Conference on Conceptual Modeling (pp. 407-414). Springer: Cham.

[38] Rivkin, J. W., \& Siggelkow, N. (2003). Balancing Search and Stability: Interdependencies among Elements Organizational Design. Management Science , 49 (3), 290-311. DOI: $10.1287 / \mathrm{mnsc} .49 .3 .290 .12740$

[39] Sadeghi, D. (2011). Alignment of organizational change strategies and its relationship with increasing organizations' performance. Procedia-Social and Behavioral Sciences, 20, 1099-1107. DOI: 10.1016/j.sbspro.2011.08.119 
[40] Sender, S. W. (1997). Systematic agreement: A theory of organizational alignment. Human Resource Development Quarterly, 8 (1), 23-40.

[41] Siggelkow, N. (2001). Change in the presence of fit: The rise, the fall, and the renaissance of Liz Claiborne. Academy of Management Journal, 44 (4), 838-857.

[42] Simons, R. (2010). Accountability and Control as Catalysts for Strategic Exploration and Exploitation: Field Study Results. Harvard Business School.

[43] Simons, R. (2005). Levers of Organization Design: How managers use accountability systems for greater performance and commitment. Boston: Harvard Business Scholl Press.

[44] Thompson, J. D. (1967). Organizations in Action. New York: McGraw-Hill.

[45] Todorovic, D. (2008). Metodologija psiholoških istraživanja. Beograd: Društvo psihologa Srbije.

[46] Trevor, J., \&Varcoe, B. (2017). How Aligned is Your Organization?Harvard Business Review.Retrieved from https://hbr.org/2017/02/how-aligned-is-your-organization

[47] Trotter, R. (2012). Qualitative research sample design and sample size: Resolving and unresolved issues and inferential imperatives. Preventive Medicine , 55, 398-400. DOI: 10.1016/j.ypmed.2012.07.003

[48] Walsh, J. P., \& Dewar, R. D. (1987). Formalization and the Organizational Life Cycle. Journal of Management Studies, 24 (3), 215-231.

[49] Walter, J., Kellermanns, F. W., Floyd, S. W., Veiga, J. F., \& Matherne, C. (2013). Strategic alignment: A missing link in the relationship between strategic consensus and organizational performance. Strategic Organization, 11 (3), 304-328. DOI: 0.1177/1476127013481155

[50] Waterman, R. H., Peters, T. J., \& Phillips, J. R. (1980). Structure is not organization. Business Horizons , 23 (3), 14-26.

[51] Wong, C. A., Elliott-Miller, P., Laschinger, H., Cuddihy, M., M. Meyer, R., Keatings, M., et al. (2015). Examining the relationships between span of control and manager job and unit performance outcomes. Journal of nursing management , 23 (2), 156-168. DOI: 10.1111/jonm.12107.

[52] Wood, J. A., \& Winston, B. E. (2007). Development of three scales to measure leader accountability. Leadership \& Organization Development Journal , 28 (2), 167-185. DOI: 10.1108/01437730710726859

[53] Woodward, J. (1958). Management and Technology. London: Her Majesty's Stationery Office.

[54] Yoo, Y., Boland Jr., R. J., \& Lyytinen, K. (2006). From Organization Design to Organization Designing. Organization Science , 17 (2), 215-229. DOI: 10.1287/orsc.1120.0771

[55] Zakari, M., \& Poku, K. (2013). Organizational Culture and Organisational Performance: Empirical Evidence from the Banking Industry in Ghana. International Journal of Business, Humanities and Technology, 3 (1), 95-107.

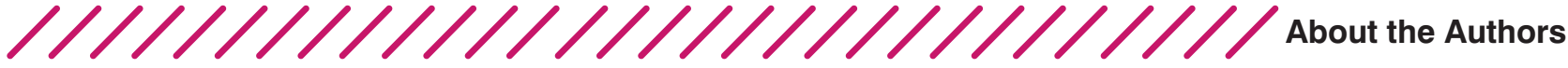

\section{Miloš Jevtić \\ University of Belgrade, Faculty of Organizational Sciences, Serbia jevticm@fon.bg.ac.rs}

Milos Jevtic works as an assistant professor at the Faculty of Organizational Sciences, University of Belgrade. During the last 12 years, he has taught Fundamentals of Organization, Organizational Design and Management of Special Events courses at undergraduate studies, as well as several subjects at master studies. His basic fields of interest are organizational design, management control systems and organizational culture. $\mathrm{He}$ is a consultant of Human Synergistics for organizational culture and effectiveness. He has published more than 50 papers in scientific and professional journals and conferences. During his work at the Faculty of Organizational Sciences, he was engaged in more than 20 commercial and scientific projects. $\mathrm{He}$ is the president of "Belgrade University Rowing Club".

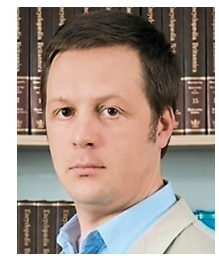




\section{Milica Jovanović \\ University of Belgrade, Faculty of Organizational Sciences, Serbia jovanovic.milica@fon.bg.ac.rs}

Milica Jovanović, MSc, works as a teaching assistant at the Faculty of Organizational Sciences, Department for Technology, Innovation and Development Management. She is completing her PhD studies at the Faculty of Organizational Sciences, University of Belgrade - Information systems and management. She has been involved in 3 consulting projects and 1 strategic project funded by the Ministry of Education, Science and Technological Development of the Republic of Serbia. She is the author and coauthor of more than 20 scientific papers. Her main research interests include:

technology and innovation management, quantitative management, sustainable development and performance management.

\section{Jovan Krivokapić \\ University of Belgrade, Faculty of Organizational Sciences, Serbia krivokapicj@fon.bg.ac.rs}

Jovan Krivokapić is an assistant professor at the Faculty of Organizational Sciences in Belgrade, at the Department for Business Systems Organization. He graduated at this faculty in 2007, in 2009 he became a master engineer of organizational sciences, and in

2016 he defended his doctoral dissertation. His areas of interest are business

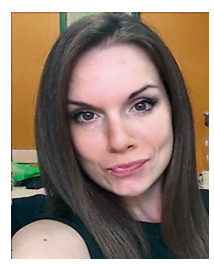

consulting, organizational design and restructuring, and special events management.

As the author or co-author, he has published 4 books and more than 40 papers in scientific journals and conferences. He has participated in more than 15 consulting and research projects and some of them were of high social significance. 